\title{
O IBRI na preparação da Cúpula de Quebec
}

\section{JOSÉ FLÁVIO SOMBRA SARAIVA}

O Instituto Brasileiro de Relações Internacionais (IBRI) não se eximiu de sua responsabilidade na ampliação do debate atinente às relações internacionais do momento. Interessado em participar das discussões preparatórias à presença brasileira na Terceira Reunião de Cúpula das Américas, realizada em abril do corrente ano em Quebec, no Canadá, o IBRI auxiliou na preparação do seminário internacional Integração Hemisférica: dimensões políticas, econômicas e sociais, realizado entre os dias 6 e 8 de dezembro de 2000, em Brasília. Tendo como organizador principal o Instituto Teotônio Vilela, o evento também contou com a colaboração do Robarts Centre for Canadian Studies.

Na ocasião, representantes do Brasil, Chile, Canadá, Estados Unidos da América e Argentina, de organizações empresariais nacionais como a Petrobras, de organizações internacionais e do meio acadêmico, reuniram-se com o objetivo de trocar experiências e conhecimentos quanto ao processo em curso de integração. As posições intelectuais e políticas foram apresentadas na amplitude do debate relativo ao processo decisório do Brasil na matéria. Daí a importância da participação do IBRI ao ter podido oferecer sua bagagem de reflexão calibrada acerca dos riscos e oportunidades que a criação da ALCA - Associação de Livre Comércio das Américas - traz para a inserção internacional do Brasil no início do novo século.

Revestiu-se de particular importância a contribuição do Presidente do Instituto Teotônio Vilela, Senador Lúcio Alcântara, ao ter proposto o argumento de que a integração hemisférica apenas poderá ser uma integração, de fato, se assentada em blocos sub-regionais consistentes - como o Mercosul, se for capaz de criar mecanismos que favoreçam a ação de empresas de menor porte, se for animadora da participação direta do Legislativo e da sociedade civil na formulação de políticas a serem adotadas e, finalmente, se estiver alicerçada na idéia de parceria, a qual, respeitando as diferenças, "pressupõe respeito à soberania de cada Estadomembro".

Como Diretor-Geral do IBRI fui convocado a expor meu ponto de vista. Fi-lo por meio da discussão acerca do momento atual das relações Brasil-Estados Unidos, artéria nervosa da ALCA, para defender uma estratégia brasileira mais cautelosa no tema da integração hemisférica. Argumentei que havia um transcurso, nas relações bilaterais entre os dois gigantes do continente americano, com 
relevância inequívoca para os desafios do presente. Único país da América Latina a participar das duas grandes conflagrações mundiais do século que se encerrou, ao lado dos aliados, e sob a liderança norte-americana, o Brasil tem um histórico de relações mais que cordiais com aquele país, sem ter caído nas tentações das relações carnais.

Nesse sentido, a maturidade acumulada da diplomacia brasileira e a ausência de mudança de rumo nas relações dos dois países permitirão, no processo de construção da ALCA, uma oportunidade de exercer o jogo dos ganhos e perdas, de vantagens compartilhadas e desvantagens igualmente postas à mesa de negociações com clareza e com o sentido da defesa dos interesses nacionais. $\mathrm{O}$ Brasil vem seguindo essa linha de trabalho, desde o campo da segurança internacional até o terreno das questões econômico-comerciais, da qual o tema da ALCA faz parte.

Propus aos presentes no seminário a questão do novo lugar estratégico do Brasil para os Estados Unidos no contexto da integração hemisférica. Perguntei sobre os interesses que se movem na direção da nova sedução norte-americana pelos seus amigos do sul das Américas. Sugeri, à guisa de contribuição ao tema e ao processo decisório brasileiro na área, o tema da definição dos interesses nacionais norte-americanos em uma economia planetária transnacionalizada em diversos setores ou tendendo à globalização, mas com interesses ainda claramente centrados no poder nacional. Embora não seja fácil encontrar um denominador comum para os interesses nacionais norte-americanos, os movimentos do processo negociador internacional dos Estados Unidos vêm sendo os de propiciar avanço quantitativo e qualitativo da sócio-economia daquele país no mundo. Nesse sentido, o espaço sulamericano é uma área preferencial na estratégia global norte-americana.

Defendi, assim, que a chamada construção hemisférica deve ser considerada no contexto das dimensões da economia norte-americana e sua dinâmica presença internacional, mesmo que em momentos de retração de produção como a atual fase. Além de agir como mola propulsora, os Estados Unidos são importantes beneficiários da transnacionalização e globalização produtiva que faz com que seus interesses nacionais extrapolem sua base territorial, tornando impossível a busca localizada de satisfação desses interesses sem que o país mantenha ativa presença global, de ordem econômica, política, militar e cultural. Trata-se, portanto, de interesses nacionais de alcance planetário estipulados justamente pela pretensa evaporação das linhas divisórias entre os âmbitos interno e externo e pelo reconhecimento de seu status de poder dominante.

O embaixador Graça Lima, diplomata que coordena o processo negociador da ALCA pelo Brasil, insistiu na idéia de que a estratégia brasileira é cheia de “transparência nas intenções”, sem segredos velados. O fato de o Brasil apresentar um comércio internacional bastante aquém de suas possibilidades, reduzido à ordem de $10 \%$ a $13 \%$ da sua capacidade de criação de riqueza, além de ser um país 
beneficiado pela dimensão do seu mercado interno, torna o país um interlocutor relevante no quadro de discussões da formação da ALCA. Há três aspectos que chamam a atenção do negociador brasileiro. Em primeiro lugar, há temores legítimos de eventuais distorções do comércio regional, provocando desequilíbrios, diante da potencialidade de evolução, para percentuais bastante mais elevados, dos atuais 19\% de comércio brasileiro com os Estados Unidos, quando comparado com o total de sua balança comercial. Nessa mesma direção, há os problemas das tarifas e dos empregos, áreas em torno das quais não se pode gerar profundas distorções na dimensão social da integração.

Em segundo lugar, na visão de Graça Lima, o "Brasil deve querer a ALCA”, mas também deve possuir uma área de livre-comércio com a União Européia e seus outros parceiros, no esforço de construção de relações competitivas. Em terceiro lugar, chamou a atenção para o fato de que a ALCA tem tudo para se constituir em um modelo novo e original de processo de integração amplo e geral, nos moldes da Organização Mundial do Comércio, com benefícios mútuos, o que supõe que não deveria ocorrer apenas a liberalização de certos produtos em detrimento de outros.

O conselheiro Antonio Simões, chefe do Núcleo da ALCA no Ministério das Relações Exteriores, observou que a proposta brasileira para a ALCA, embora nunca formalmente aceita, foi religiosamente cumprida. A tese de um processo mais dilatado no tempo ganhou força, como se percebeu nas decisões da Cúpula de Quebec e antes na Reunião Ministerial de Buenos Aires, ganhou força diante das circunstâncias complicadas da negociação, a maioria delas criadas pelo próprio processo decisório norte-americano na matéria. Foi assim que se procedeu no caso da Reunião Ministerial de Toronto, de novembro de 1999 e logo depois da Rodada do Milênio (Seattle), quando apenas a minuta de acordo da ALCA tinha sido preparada.

Essencial foi a contribuição de Gianneti da Fonseca, da CAMEX - Câmara de Comércio Exterior - ao expor os riscos e oportunidades criadas pelo impacto da ALCA sobre o comércio exterior do Brasil. Debateu, em especial, algumas das dificuldades na preparação da Cúpula de Quebec. Enfatizou, em primeiro lugar, o caráter extremamente complexo das negociações, tendo em vista a heterogeneidade dos grupos participantes, seus interesses e estruturas econômicas bastante diferenciadas. Nesse sentido, tornar-se-ia necessária uma trajetória de convergência macroeconômica como precedente básico para uma posterior eliminação de graves distorções competitivas.

Em segundo lugar, observou Gianneti da Fonseca, a ALCA vem plasmada pela visão normalmente conservadora e imediatista dos empresários. Seria necessário reverter essa visão na busca de vantagens relativas e resultados equilibrados para os parceiros. Ao lado do processo negociador são também 
necessários ajustes e reformas internas para corrigir desvantagens competitivas, especialmente, por mecanismos tributários, financeiros e logísticos.

$\mathrm{O}$ terceiro aspecto proposto pelo economista brasileiro vincula-se às oportunidades e aos riscos que a ALCA cria para países como o Brasil no mercado norte-americano. Afirmou que é necessário romper, no contexto negociador da ALCA, o viés protecionista dos Estados Unidos dirigido contra 15 produtos brasileiros naquele mercado. No caso do açúcar, persiste ridícula participação do Brasil, inferior à do Caribe e das Filipinas. No caso do suco de laranja, fornece o Brasil cerca de $90 \%$ da importação norte-americana do produto, mesmo que ainda sujeito a tarifas da ordem de $44,7 \%$. Os produtores siderúrgicos continuam sendo o alvo predileto das ações anti-dumping e do protecionismo geriátrico de tipo mais perverso. Os calçados vêm recebendo $8 \%$ a $10 \%$ de impostos. Os têxteis e confecções brasileilras no mercado norte-americano respondem, nos dias atuais, por cerca de um terço do que representavam em 1994. O mesmo pode ser dito do etanol, das ligas de ferro, dos tubos de silício-metálico, entre tantos outros itens. As posições brasileiras são, para completar o ciclo das diferenças fundamentais no processo negociador com os Estados Unidos, diametralmente diferentes no caso da agricultura, dos regimes de propriedade intelectual, compras governamentais, serviços e política de concorrência.

A inserção argentina na ALCA foi também objeto do seminário. O professor Felix Peña, do Conselho Argentino para as Relações Internacionais (CARI), iniciou sua apresentação fazendo referência às palavras de Celso Lafer ao definir a política exterior como a "arte de conciliar necessidades internas com possibilidades externas”. Para a Argentina, a máxima tem uma aplicação muito clara. Há necessidades estruturais internas que exibem uma posição ativa da Argentina no tema da ALCA como a geração de insumos para a modernização, particularmente via recursos tecnológicos, e a geração de um ambiente político satisfatório para o desenvolvimento da democracia.

Nesse sentido, as prioridades argentinas, para Felix Peña, vem sendo organizadas em torno do fortalecimento da Organização Mundial do Comércio e do relançamento do Mercosul, como projeto político-estratégico no qual o Chile está incluído. No que se refere à integração hemisférica, a Argentina tende a aceitar com forte interesse, nas palavras do professor, a integração hemisférica sob o prisma do artigo 24 do GATT, diante dos quadros de incerteza que vão sendo gradualmente diluídos. Mas a Argentina negocia a ALCA a partir do Mercosul, com uma dimensão sul-americana, ao lado do Brasil, mantendo coerência e afinidade substantiva. Defende a Argentina, assim como o Brasil, a negociação por consenso, mantendo a lógica do single undertaking.

Jean Daudelin, estudioso canadense, fez duras críticas à forma pela qual se vem aplicando o multilateralismo no continente. Sublinhou o sentido quase religioso, ou de doutrina oficial, com que o multilateralismo vem sendo tratado. 
Citou o caso da Austrália, da África do Sul e também o do Brasil. Referiu-se, em especial, ao Canadá como um ativista nessa área, portador que é de uma atitude de vanguarda na tese multilateralista. O interessante, para Daudelin, é o fato de tal atitude, em certa medida, apresentar-se como contraditória com a tradicional posição canadense de cautela e prudência diante dos esquemas do multilateralismo. Ressaltou, referindo-se à posição do Brasil na construção hemisférica, que o mercado brasileiro corresponde à grande caça da ALCA. Daí a importância de uma posição de estudo e observância, por parte do Brasil, nas matérias a serem discutidas até 2005.

A dimensão social do projeto hemisférico e a participação da sociedade civil no processo foram também objeto do seminário internacional. Nesse sentido foi essencial a contribuição do professor Yves Chaloult, da Universidade de Brasília. Destacou a dificuldade de se imaginar a possibilidade de desenvolvimento de uma governança compartilhada diante das assimetrias presentes no contexto das Américas. Segundo Chaloult, países de mão-de-obra intensiva irão resistir melhor ao processo de integração. Criticou o fato de os empresários terem rapidamente se organizado, estabelecendo seus fóruns consultivos, mas que a sociedade civil está ainda bastante alienada das discussões em curso. Sublinhou que existe um espaço na ALCA para políticas públicas, uma vez que o mercado não resolverá todas as questões. No sentido propositivo, o expositor insistiu na necessidade de criação de uma aliança social continental para fazer avançar a dimensão social da ALCA e sua participação cidadã. Para tal seria necessária uma ampliação do grupo negociador, com a inclusão de novos atores sociais.

Nessa mesma linha de ampliação do grupo negociador, em especial com a participação do setor privado, pareceu essencial a contribuição de dois pontos de vista. Um primeiro, de matriz norte-americana, sugerido por David Lewis, da empresa Manchester Trade, ao mencionar o interesse do seu país menos no intercâmbio comercial e mais na dimensão produtiva do projeto de integração hemisférica. Nesse sentido, os interesses norte-americanos estariam se guiando majoritariamente no sentido de garantir vantagens futuras para a instalação dos grandes atores nos principais mercados consumidores da região do que propriamente por garantir pequenas vantagens comerciais nesses mercados.

Ao mesmo tempo, para Lewis, o atual momento político nos Estados Unidos propicia um debate burocrático interno, quase silencioso, em torno do formato adequado, para todos os setores, acerca da integração comercial desejável. Não se conhece ainda, para o representante do setor privado norte-americano, o modelo de negociações que se implementará no futuro próximo, a depender das visões específicas que os diferentes grupos possuem no interior do aparelho de Estado, particularmente no que se refere a velocidades e intensidades do processo de integração comercial. 
Um ponto de vista brasileiro na questão empresarial foi apresentado por Julio Bueno, diretor da BR Petrobras Distribuidora. Salientou a estratégia de fortalecimento da empresa no espaço regional da América do Sul, na perspectiva de apresentar base produtiva mais avançada diante da crescente e inevitável implementação do projeto da ALCA. Citou, por exemplo, a criação da Petrobras Bolívia (PEB), baseada na intensificação das atividades de exploração e sobretudo na conclusão do gasoduto Brasil-Bolívia, ao que se somam a aquisição de refinarias, a implantação de rede de postos de serviços e a comercialização direta de derivados e lubrificantes; a criação da Petrobras Argentina (PAR), mediante a troca de ativos com a Repsol-YPF, o adensamento na participação no sistema de transporte por gasodutos e igualmente a exploração, produção e comercialização direta de derivados e lubrificantes; a criação da Petrobras América (PAI) para exportação de gasolina e a exploração direta de petróleo no Golfo do México; e, finalmente, a criação, no Paraguai, Uruguai, Colômbia, Trinidad e Tobaco, Equador e Peru, mas sobretudo na Venezuela, de conexões profundas no campo da comercialização de derivados, combustíveis e lubrificantes, bem como na exploração e produção direta.

Em conclusão, o seminário internacional Integração Hemisférica: dimensões políticas, econômicas e sociais foi um marco na participação do IBRI na formação da opinião pública em matéria internacional. O profícuo debate estabelecido sobre as múltiplas dimensões da integração hemisférica durante o seminário convergiu para a elaboração de uma síntese e de agenda propositiva que pode servir como base para a reflexão tanto do Governo quanto do Parlamento e demais atores sociais interessados nesse processo. Ambos os documentos, publicados na série Idéias \& Debate, do Instituto Teotônio Vilela (número 43, abril de 2001), acompanharam a delegação brasileira na sua participação na Cúpula de Quebec. 